MARTINS, J.M.S. et al. Desempenho zootécnico de linhagens de frango de corte de crescimento rápido. PUBVET, Londrina, V. 6, N. 4, Ed. 191, Art. 1287, 2012.

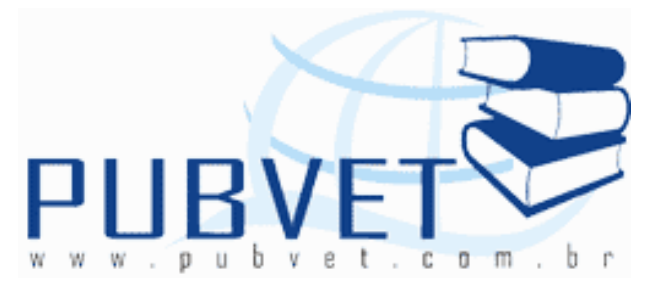

PUBVET, Publicações em Medicina Veterinária e Zootecnia.

\title{
Desempenho zootécnico de linhagens de frango de corte de crescimento rápido
}

\section{Julyana Machado da Silva Martins ${ }^{1}$; Rodrigo Zaiden Taveira ${ }^{2}$; Fernanda Heloisa} Hitz $^{3}$; Henrique Castilhano ${ }^{4}$; Mariane Pacheco dos Santos ${ }^{5}$

\author{
${ }^{1}$ Aluna do curso de Zootecnia da UEG \\ ${ }^{2}$ Docente do curso de Zootecnia da UEG \\ ${ }^{3}$ Aluna de pós-graduação em Ciências Veterinárias - FAMEV-UFU \\ ${ }^{4}$ Analista de Originação JBS \\ ${ }^{5}$ Médica Veterinária autônoma
}

\section{Resumo}

O crescimento da avicultura tem como base a melhoria constante no melhoramento genético das linhagens. Assim, objetivou-se avaliar o desempenho zootécnico de diferentes linhagens de frango de corte de crescimento rápido. Foram avaliados o desempenho zootécnico de três linhagens comerciais de crescimento rápido, A, B e C, de lotes com machos, fêmeas e mistos. As variáveis utilizadas foram peso médio, ganho médio de peso, conversão alimentar, viabilidade e índice de eficiência produtiva. Observou-se que o peso médio das aves, e a conversão alimentar não foram influenciados pela linhagem ( $P>0,05)$. Já quando comparado o peso médio e a conversão alimentar entre machos, fêmeas e lotes mistos, observou-se diferenças significativas $(P<0,05)$. Houve diferença significativa $(P<0,05)$ para 
MARTINS, J.M.S. et al. Desempenho zootécnico de linhagens de frango de corte de crescimento rápido. PUBVET, Londrina, V. 6, N. 4, Ed. 191, Art. 1287, 2012.

ganho médio de peso, quando comparadas fêmeas de diferentes linhagens. Quando comparados lotes de machos, fêmeas e mistos, constatou-se diferenças significativas $(P<0,05)$ para as linhagens $B$ e $C$. Observou-se que a linhagem A apresentou maiores índices de viabilidade e IEP que as demais linhagens, tanto para lotes de machos, fêmeas e mistos. As fêmeas apresentaram maiores viabilidades que machos e lotes mistos, nas três linhagens comparadas. E para IEP, os machos obtiveram melhores resultados. Assim, observou-se efeito da linhagem no ganho médio de peso, viabilidade e índice de eficiência produtiva, das linhagens analisadas. O sexo influenciou no desempenho das linhagens, onde lotes de machos obtiveram melhores resultados para as variáveis peso médio, ganho médio de peso, conversão alimentar e índice de eficiência produtiva. Constatando melhor desempenho de lotes de fêmeas apenas para a viabilidade criatória.

Palavras-chave: Avicultura, Conversão Alimentar, Índice de Eficiência Produtiva, Ganho Médio de Peso, Peso Médio, Viabilidade.

\section{Zootechnical efficiency of fast growth broiled chicken breeds}

\section{Abstract}

The poultry industry growth is based on the constant improving in genetic improvement of breeds. The objective was to evaluate the efficiency of different breeds of fast growth broiler chickens. Growth performance of three commercial fast breeds growth, A, B and C, with male, female and mixed flocks were analyzed. The variables used were weight average, daily gain average, feed efficiency, viability and productive efficiency rates. It was observed that birds' average weight and feed were not affected by breeds $(P>0.05)$. However, when compared the average weight and feed conversion among males, females and mixed flocks, there was a significant difference $(P<0.05)$. Statistically significant $(P<0.05)$ for average weight gain when compared females of different breeds. When compared male, female and mixed flocks, there are significant differences $(P<0.05)$ for breeds $B$ and $C$. It 
MARTINS, J.M.S. et al. Desempenho zootécnico de linhagens de frango de corte de crescimento rápido. PUBVET, Londrina, V. 6, N. 4, Ed. 191, Art. 1287, 2012.

was observed that breed $A$ had higher rates of viability and PER than the other breeds, as for male, female and mixed flocks. Females had higher viability than males, and mixed flocks, in the three breeds compared. And for PER, males had better results. The effect of lineage weight gain average was observed, and also viability and productive efficiency rates, of lineage analyzed. Sex affected lineage performance, where male lots had better results for average weight variables, average weight gain, feed conversion and productive efficiency rate. Noting best performance on female lots only for raising viability.

Keywords: Average Weight, Average Weight Gain, Aviculture, Feed Conversion, Productive Efficiency Rate, Viability.

\section{Introdução}

A avicultura industrial brasileira tem se expandindo a cada ano, devido aos avanços tecnológicos nas áreas de genética, nutrição e sanidade, tendo sido impulsionada pelo crescimento da demanda associada à mudança no padrão de consumo.

A competitividade e a evolução da indústria avícola brasileira têm estimulado a constante busca da melhoria do material genético dos frangos de corte. Pesquisas avaliando esses produtos são realizadas a fim de identificar linhagens com características superiores em relação a outras, selecionando, dessa forma, aves que apresentem melhor desempenho (STRINGHINI et al., 2003).

A indústria avícola, graças a seu dinamismo decorrente da estreita interação com a genética, fez com que as aves se tornassem, um exemplo de eficiência em produção de alimento de excelente qualidade (PAIVA et al., 2004). O potencial genético do frango moderno avança por meio da seleção, onde os métodos utilizados para obtenção da eficiência produtiva são fatores decisivos para a avaliação do sucesso em um programa de melhoramento genético, no qual se exige animais cada vez mais produtivos (MADEIRA et al., 2006; TEIXEIRA et al., 2004). 
MARTINS, J.M.S. et al. Desempenho zootécnico de linhagens de frango de corte de crescimento rápido. PUBVET, Londrina, V. 6, N. 4, Ed. 191, Art. 1287, 2012.

PAIVA et al. (2004), registram que os programas de melhoramento necessitam de constante acompanhamento das características de importância econômica de cada linhagem e de seus cruzamentos. Dentre estas características, podem ser citadas o ganho em peso, a conversão alimentar e a viabilidade.Pois a partir destes estudos é que os critérios de seleção são estabelecidos para garantir a renovação dos planteis com animais de potencial genético superior, geração após geração.

Dessa forma, as linhagens de frangos de corte, comercialmente disponíveis, apresentam potenciais genéticos diferenciados devido à pressão de seleção aplicada para cada uma das características de interesse econômico (ARAÚJO et al., 2002; SANTOS, 2008).

Assim, objetivou-se avaliar o desempenho zootécnico de diferentes linhagens de frango de corte de crescimento rápido.

\section{Materiais e Métodos}

Os dados utilizados no presente trabalho foram provenientes de aviários integrados a uma empresa do estado de Goiás, sendo que em cada galpão eram alojadas 21.000 aves.

As aves foram alojadas em galpões convencionais de alvenaria, de $12 \mathrm{~m} \times$ $125 \mathrm{~m}$. Os pintos foram vacinados no incubatório contra a doença de Marek e aos 10 dias de idade contra as doenças de Gumboro e Newcastle, via água de bebida. O programa de iluminação adotado foi o de 23 horas de luz por dia. Diariamente eram controladas as temperaturas máximas e mínimas no interior dos aviários.

As aves recebiam água e comida ad libitum. O programa alimentar adotado foi o de quatro fases de criação atendendo às exigências nutricionais dos frangos em cada fase de vida, sendo considerada fase pré-inicial a de 1 a 7 dias, inicial a de 8 a 21 dias, crescimento a de 22 a 28 dias, e fase final, de 29 dias de idade ao abate. Nas fases de crescimento e final, a alimentação era diferenciada para machos e fêmeas. 
MARTINS, J.M.S. et al. Desempenho zootécnico de linhagens de frango de corte de crescimento rápido. PUBVET, Londrina, V. 6, N. 4, Ed. 191, Art. 1287, 2012.

$\mathrm{Na}$ Tabela 1 pode-se verificar as composições nutricionais das rações fornecidas nas fases pré-inicial, inicial, crescimento macho e crescimento fêmea.

Tabela 1. Composições nutricionais das rações Pré-Inicial, Inicial, Crescimento Macho e Crescimento Fêmea.

\begin{tabular}{|c|c|c|c|c|}
\hline Ingredientes & $\begin{array}{c}\text { Pré- } \\
\text { Inicial }\end{array}$ & Inicial & $\begin{array}{c}\text { Crescimento } \\
\text { Macho }\end{array}$ & $\begin{array}{c}\text { Crescimento } \\
\text { Fêmea }\end{array}$ \\
\hline Milho Grão & 883,698 & 898,896 & $1.024,050$ & $1.039,255$ \\
\hline Farelo de Soja $46 \%$ & 465,000 & 264,000 & - & - \\
\hline Farelo de Soja $48 \%$ & - & - & 259,000 & 294,000 \\
\hline Soja Tostada & - & 216,000 & - & - \\
\hline Farinha de Penas & - & - & 31,000 & - \\
\hline Farinha de Víscera & - & 33,000 & 35,000 & 22,000 \\
\hline Farinha de Sangue & 30,000 & - & 20,000 & 20,000 \\
\hline Farinha de Carne & 68,000 & 50,000 & 48,000 & 50,000 \\
\hline Gordura de Aves & 14,000 & - & 44,000 & 38,000 \\
\hline Sal Branco Comum & 5,700 & 5,100 & 3,800 & 4,300 \\
\hline Calcário & 8,000 & 8,000 & 8,000 & 8,000 \\
\hline Aji -lys $64 \%^{1}$ & 4,966 & 5,701 & 7,291 & 4,998 \\
\hline Colina $75 \%{ }^{2}$ & 1,088 & 0,680 & 0,957 & 0,835 \\
\hline Sulfato de Cobre & 0,450 & 0,500 & 0,500 & 0,500 \\
\hline Saltract ${ }^{3}$ & 0,474 & 0,210 & 0,327 & 0,336 \\
\hline Bicarbonato & 2,000 & 1,500 & 2,500 & 2,500 \\
\hline DL-Metionina $98 \%{ }^{4}$ & 5,850 & 4,700 & 4,350 & 4,050 \\
\hline Premix e Aditivos & 10,774 & 11,713 & 11,225 & 11,226 \\
\hline Batida Total (kg) & $1.500,000$ & $1.500,000$ & $1.500,000$ & $1.500,000$ \\
\hline
\end{tabular}

$\mathrm{Na}$ Tabela 2 pode-se observar as composições nutricionais das rações fornecidas para a fase final, sendo diferenciada para machos e fêmeas. 
MARTINS, J.M.S. et al. Desempenho zootécnico de linhagens de frango de corte de crescimento rápido. PUBVET, Londrina, V. 6, N. 4, Ed. 191, Art. 1287, 2012.

Tabela 2. Composições nutricionais das rações Final Macho e Final Fêmea.

\begin{tabular}{ccc}
\hline Ingredientes & Final Macho & Final Fêmea \\
\hline Milho Grão & $1.108,155$ & $1.128,427$ \\
Farelo de Soja & 172,000 & 169,000 \\
Farinha de Penas & 40,000 & 40,000 \\
Farinha de Vísceras & 35,000 & 30,000 \\
Farinha de Sangue & 20,000 & 20,000 \\
Gordura de Aves & 43,000 & 34,000 \\
Farinha de Carne & 41,000 & 43,000 \\
Sal Branco Comum & 3,800 & 4,000 \\
Calcário & 8,000 & 7,000 \\
Alimet 80\% & 3,450 \\
Aji -lys 64\% $^{2}$ & 5,150 & 6,512 \\
Colina 75\% $^{3}$ & 9,210 & 0,829 \\
Saltract & 0,912 & 0,307 \\
Bicarbonato Sódio & 0,298 & 2,700 \\
Premix e Aditivos & 2,700 & 10,775
\end{tabular}

\section{Batida Total $(\mathrm{kg}) \quad 1.500,000 \quad 1.500,000$}

${ }^{1}$ Metionina líquida ; ${ }^{2}$ Lisina; ${ }^{3}$ Aminoácido; ${ }^{4}$ Produto anti-salmonela usado nos produtos de origem animal.

A Tabela 3 apresenta os níveis nutricionais das rações fornecidas para as fases pré-inicial, inicial, crescimento macho e crescimento fêmea.

$\mathrm{Na}$ Tabela 4 pode-se verificar os níveis nutricionais das rações fornecidas para a fase final, onde a ração nesta fase é diferente para machos e fêmeas.

Foi avaliado o desempenho zootécnico de três linhagens comerciais de crescimento rápido, $\mathrm{A}, \mathrm{B}$ e $\mathrm{C}$, de lotes com machos, fêmeas e mistos. As variáveis utilizadas foram peso médio, ganho médio de peso, conversão alimentar, viabilidade e índice de eficiência produtiva.

Para a obtenção do peso médio, foi calculada a diferença entre as pesagens no início e final da criação. E para o ganho médio de peso, foi dividido o peso médio do lote pela idade em dias. 
MARTINS, J.M.S. et al. Desempenho zootécnico de linhagens de frango de corte de crescimento rápido. PUBVET, Londrina, V. 6, N. 4, Ed. 191, Art. 1287, 2012.

Tabela 3. Níveis nutricionais das rações Pré-Inicial, Inicial, Crescimento Macho e Crescimento Fêmea.

\begin{tabular}{ccccc}
\hline Nutrientes & $\begin{array}{c}\text { Pré- } \\
\text { Inicial }\end{array}$ & Inicial & $\begin{array}{c}\text { Crescimento } \\
\text { Macho }\end{array}$ & $\begin{array}{c}\text { Crescimento } \\
\text { Fêmea }\end{array}$ \\
\hline PB (\%) & 23,479 & 21,745 & 20,022 & 18,977 \\
Cálcio (\%) & 0,997 & 0,929 & 0,907 & 0,875 \\
Ca/P & 2,000 & 1,971 & 1,967 & 1,979 \\
P Total (\%) & 0,630 & 0,606 & 0,559 & 0,549 \\
EM(Kcal/Kg) & $3.011,321$ & $3.128,858$ & $3.267,938$ & $3.239,431$ \\
Lisina (\%) & 1,444 & 1,313 & 1,208 & 1,134 \\
aa Total (\%) & 1,074 & 0,972 & 0,941 & 0,852 \\
Trp Total (\%) & 0,267 & 0,239 & 0,203 & 0,203 \\
Trp/Lisina & 0,178 & 0,174 & 0,161 & 0,172 \\
Na+K+ClmEq & 230,130 & 220,461 & 171,626 & 181,856 \\
\hline
\end{tabular}

Tabela 4. Níveis nutricionais das rações Final Macho e Final Fêmea.

\begin{tabular}{ccc}
\hline Nutrientes & Final Macho & Final Fêmea \\
\hline PB (\%) & 17,992 & 17,657 \\
Cálcio (\%) & 0,839 & 0,819 \\
Ca/P & 1,969 & 1,922 \\
P Total (\%) & 0,511 & 0,513 \\
P.Disponível (\%) & 0,426 & 0,426 \\
EM (Kcal/Kg) & $3.318,480$ & $3.290,466$ \\
Lisina Total (\%) & 1,114 & 1,014 \\
aa Total (\%) & 0,889 & 0,795 \\
Trp Total (\%) & 0,171 & 0,170 \\
Na+K+ClmEq & 146,434 & 146,711 \\
\hline
\end{tabular}


MARTINS, J.M.S. et al. Desempenho zootécnico de linhagens de frango de corte de crescimento rápido. PUBVET, Londrina, V. 6, N. 4, Ed. 191, Art. 1287, 2012.

As aves mortas eram registradas diariamente, para o cálculo da viabilidade, obtida através da diferença de $100 \%$ pela porcentagem de mortalidade. A porcentagem de mortalidade foi obtida pela relação entre o número de aves mortas e o número inicial de aves.

Para a obtenção da conversão alimentar foi calculada a razão entre o total de ração consumida e o ganho de peso no período.

O Índice de Eficiência Produtiva varia em função da Viabilidade (VB), do Ganho Médio de Peso Diário (GMD) e da Conversão Alimentar (CA), na retirada do lote. Este foi calculado através da seguinte fórmula:

IEP $=$ Ganho Médio de Peso $(\mathrm{Kg}) \times$ Viabilidade (\%) $\times 100$

Conversão alimentar

As análises estatísticas foram realizadas pelo programa Instat (2006) e as médias comparadas pelo teste de Tukey $(P<0,05)$.

\section{Resultados e Discussão}

A Tabela 5 demonstra os valores encontrados para peso médio das três linhagens avaliadas, de lotes formados por machos, fêmeas e mistos.

Tabela 5. Valores médios e desvios padrões calculados para Peso Médio (PM) das linhagens $A, B$ e $C$ de crescimento rápido, de lotes de machos, fêmeas e mistos.

\begin{tabular}{lccc}
\hline & \multicolumn{3}{c}{ Linhagens } \\
\cline { 2 - 4 } & \multicolumn{1}{c}{ A } & B & C \\
\hline Machos & $2,620 \pm 0,028 \mathrm{aA}$ & $2,849 \pm 0,069 \mathrm{aA}$ & $2,712 \pm 0,060 \mathrm{aA}$ \\
Fêmeas & $2,245 \pm 0,015 \mathrm{aA}$ & $2,531 \pm 0,115 \mathrm{aA}$ & $2,332 \pm 0,042 \mathrm{aB}$ \\
Mistos & $2,546 \pm 0,152 \mathrm{aA}$ & $2,675 \pm 0,026 \mathrm{aA}$ & $2,651 \pm 0,043 \mathrm{aA}$ \\
\hline Médias seguidas da mesma letra não diferenciam entre si pelo teste de Tukey (P>0,05). \\
Letras minúsculas usadas para comparação das linhagens na linha e letras maiúsculas \\
para comparação dos lotes de machos, fêmeas e mistos na coluna. \\
CV=2,632\%
\end{tabular}


MARTINS, J.M.S. et al. Desempenho zootécnico de linhagens de frango de corte de crescimento rápido. PUBVET, Londrina, V. 6, N. 4, Ed. 191, Art. 1287, 2012.

Observou-se que o peso médio das aves não foi influenciado pela linhagem ( $P>0,05)$. Da mesma forma MURAKAMI et al. (1995) e STRINGHINI et al. (2003), não encontraram diferenças estatísticas $(P>0,05)$ no peso das diferentes linhagens de crescimento rápido.

Entretanto OLMOS (2008) e MARCATO et al. (2010), evidenciaram que a linhagem Cobb apresentou uma maior taxa de crescimento e deposição de nutrientes, atingindo um maior peso, quando comparada a linhagem Ross.

Já quando comparado o peso médio entre machos, fêmeas e lotes mistos, observou-se que fêmeas da linhagem $C$ obtiveram um menor peso em relação a lotes de machos e mistos da mesma linhagem. STRINGHINI et al. (2003) e MARCATO et al. (2010), também encontraram diferenças significativas $(P<0,05)$, quando compararam machos e fêmeas de diferentes linhagens, constatando um maior desempenho para os machos.

$\mathrm{Na}$ tabela 6 são apresentados os valores encontrados para ganho médio de peso das linhagens avaliadas, para machos, fêmeas e lotes mistos.

Tabela 6. Valores médios e desvios padrões calculados para Ganho Médio de Peso (GMD) das linhagens A, B e C de crescimento rápido, de lotes de machos, fêmeas e mistos.

\begin{tabular}{lccc}
\hline & \multicolumn{3}{c}{ Linhagens } \\
\cline { 2 - 4 } & A & B & C \\
\hline Machos & $59,52 \pm 0,46 a A$ & $62,93 \pm 2,20 a A$ & $61,34 \pm 2,51 \mathrm{aA}$ \\
Fêmeas & $51,05 \pm 0,50 \mathrm{bA}$ & $55,59 \pm 1,19 \mathrm{aB}$ & $52,11 \pm 1,93 \mathrm{abB}$ \\
Mistos & $58,67 \pm 5,24 \mathrm{aA}$ & $60,83 \pm 1,07 \mathrm{aAB}$ & $58,21 \pm 1,27 \mathrm{aAB}$ \\
\hline Médias seguidas da mesma letra não diferenciam entre si pelo teste de Tukey (P>0,05). \\
Letras minúsculas usadas para comparação das linhagens na linha e letras maiúsculas \\
para comparação dos lotes de machos, fêmeas e mistos na coluna. \\
CV=3,15\%
\end{tabular}

Houve diferença significativa $(P<0,05)$ para ganho médio de peso, quando comparadas fêmeas de diferentes linhagens. Observou-se que fêmeas 
MARTINS, J.M.S. et al. Desempenho zootécnico de linhagens de frango de corte de crescimento rápido. PUBVET, Londrina, V. 6, N. 4, Ed. 191, Art. 1287, 2012.

da linhagem $B$ obtiveram maior ganho de peso médio $(P<0,05)$ quando comparada com a linhagem $A$, mais não se diferiram da linhagem $C$, e esta não se diferiu de A e B. STRINGHINI et al. (2003), não encontraram diferenças significativas $(P>0,05)$ entre as linhagens Ross, Cobb, Avian Farms e Arbor Acres, quando compararam ganho médio de peso.

Porém, GARCIA NETO e CAMPOS (2004), observaram que as aves da linhagem Cobb apresentaram o menor ganho de peso comparada as linhagens Hubbard e Ross, evidenciando que as diferenças nas curvas de crescimento devem-se as características genéticas.

Quando comparados lotes de machos, fêmeas e mistos, constatou-se diferenças significativas $(P<0,05)$ para as linhagens $B$ e $C$. Em ambas as linhagens, os machos e os lotes mistos demonstraram ganho médio de peso superior que as fêmeas. Isto é creditado ao fato de que os machos levam menos tempo para serem abatidos. STRINGHINI et al. (2003), também encontraram diferenças significativas $(P<0,05)$, onde machos demonstraram melhor desempenho.

A Tabela 7 apresenta as médias encontradas para conversão alimentar dos lotes de machos, fêmeas e mistos.

Tabela 7. Valores médios e desvios padrões calculados para Conversão Alimentar ( $\mathrm{CA}$ ) das linhagens A, B e C de crescimento rápido, de lotes de machos, fêmeas e mistos.

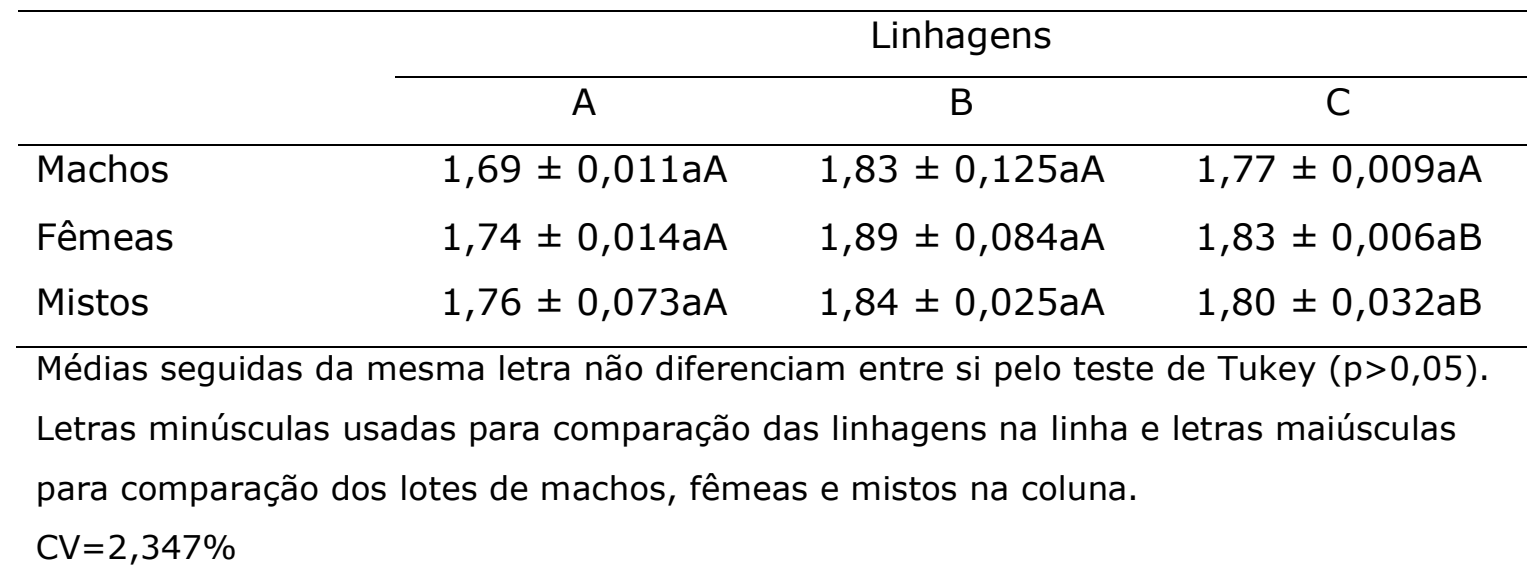


MARTINS, J.M.S. et al. Desempenho zootécnico de linhagens de frango de corte de crescimento rápido. PUBVET, Londrina, V. 6, N. 4, Ed. 191, Art. 1287, 2012.

Verificou-se que não houve diferenças significativas $(P>0,05)$ quando analisada a conversão alimentar das linhagens. Entretanto observou-se efeito do sexo nesta característica, onde machos da linhagem C apresentaram melhor conversão alimentar $(P<0,05)$ que fêmeas e lotes mistos da mesma linhagem.

STRINGHINI et al. (2003), não observaram diferenças significativas $(P>0,05)$ entre as linhagens quando compararam a conversão alimentar. Já HOLSHEIMER e VEERKAMP (1992) e SOUZA et al. (1994) detectaram melhor conversão alimentar de frangos Ross quando comparados com Cobb. GARCIA NETO e CAMPOS (2004), relataram que a conversão alimentar foi afetada significativamentepela linhagem, e os melhores resultados foram obtidosem aves da linhagem Ross, quando comparadas com a linhagem Cobb e Hubbard. Foram observadas diferenças significativas favoráveis aos machos em relação à conversão alimentar, a partir da quarta semana.

Na Tabela 8 são apresentados os dados de viabilidade em porcentagem, das linhagens $A, B$ e $C$ dos lotes analisados.

Tabela 8. Porcentagem da Viabilidade Criatória (VB) das linhagens A, B e C de crescimento rápido, de lotes de machos, fêmeas e mistos.

\begin{tabular}{lccc}
\hline & \multicolumn{3}{c}{ Linhagens } \\
\cline { 2 - 4 } & $\mathrm{A}$ & $\mathrm{B}$ & $\mathrm{C}$ \\
\hline Machos & $97,70 \%$ & $96,03 \%$ & $96,26 \%$ \\
Fêmeas & $98,02 \%$ & $97,42 \%$ & $97,50 \%$ \\
Mistos & $96,92 \%$ & $96,32 \%$ & $97,14 \%$ \\
\hline
\end{tabular}

Observou-se que a linhagem A apresentou maiores índices de viabilidade que as demais linhagens, tanto para lotes de machos, fêmeas e mistos. E que as fêmeas apresentaram maiores viabilidades que machos e lotes mistos, nas três linhagens comparadas.

Na Tabela 9 e na Figura 1 obteve-se o índice de eficiência produtiva das linhagens $A$, B e $C$ de lotes de machos, fêmeas e mistos. 
MARTINS, J.M.S. et al. Desempenho zootécnico de linhagens de frango de corte de crescimento rápido. PUBVET, Londrina, V. 6, N. 4, Ed. 191, Art. 1287, 2012.

Tabela 9. Porcentagem do Índice de Eficiência Produtiva (IEP) das linhagens A, B e C de crescimento rápido, de lotes de machos, fêmeas e mistos.

\begin{tabular}{lccc}
\hline & \multicolumn{3}{c}{ Linhagem } \\
\cline { 2 - 4 } & $\mathrm{A}$ & $\mathrm{B}$ & $\mathrm{C}$ \\
\hline Machos & $344,07 \%$ & $330,89 \%$ & $332,90 \%$ \\
Fêmeas & $286,44 \%$ & $286,17 \%$ & $276,40 \%$ \\
Mistos & $323,25 \%$ & $318,27 \%$ & $314,00 \%$ \\
\hline
\end{tabular}

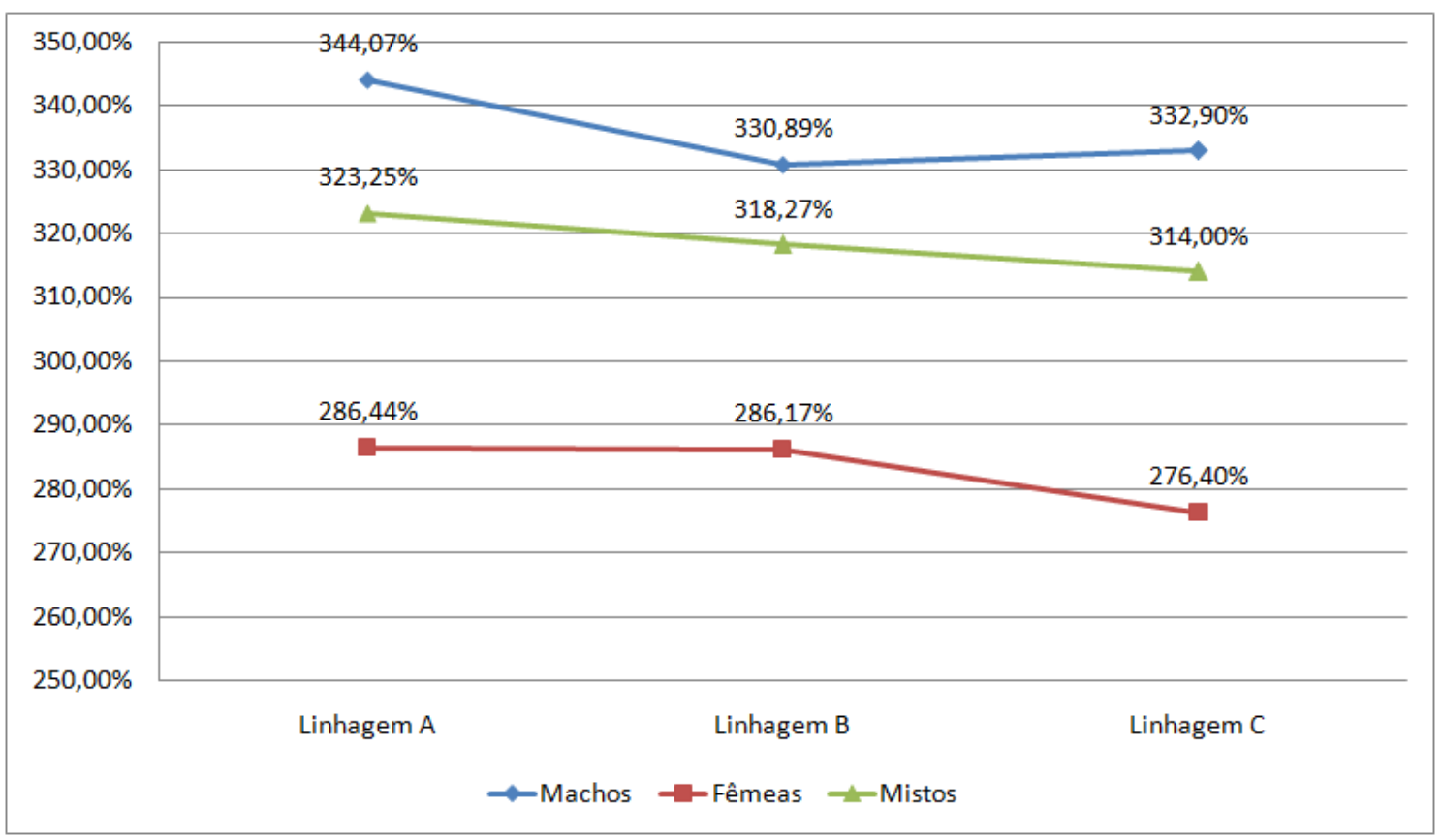

Figura 1. Representação gráfica do Índice de Eficiência Produtiva (IEP) em porcentagem das linhagens $A, B$ e $C$ de crescimento rápido, de lotes de machos, fêmeas e mistos.

Constatou-se maiores índices de eficiência produtiva, para lotes da linhagem A, devido os índices de viabilidade dos mesmos serem maiores que os demais lotes, e a conversão alimentar ser menor, esses fatores refletiram em maiores IEP.

Também observou-se maiores índices de eficiência produtiva, para lotes de machos, estes apesar de não terem maiores índices de viabilidade que lotes de fêmeas e mistos, apresentam menores índices de conversão alimentar e 
MARTINS, J.M.S. et al. Desempenho zootécnico de linhagens de frango de corte de crescimento rápido. PUBVET, Londrina, V. 6, N. 4, Ed. 191, Art. 1287, 2012.

maiores valores de ganho médio de peso, valores que contribuíram para um maior Índice de Eficiência Produtiva.

\section{Conclusão}

Observou-se efeito da linhagem no ganho médio de peso, viabilidade e índice de eficiência produtiva, das linhagens analisadas.

O sexo influenciou no desempenho das linhagens, onde lotes de machos obtiveram melhores resultados para as variáveis peso médio, ganho médio de peso, conversão alimentar e índice de eficiência produtiva. Constatando melhor desempenho de lotes de fêmeas apenas para a viabilidade criatória.

\section{Referências Bibliográficas}

ARAÚjO, C. S. S. et al. Avaliação do Desempenho e Excreção de Cálcio em Duas Linhagens de Frangos de Corte, na Fase Inicial, Alimentados com Diferentes Níveis de Aminoácidos e de Cálcio. Revista Brasileira de Ciência Avícola, v.4, n.2, p. 111-118, 2002.

GARCIA NETO, M.; CAMPOS, E. J. Suscetibilidade de Linhagens de Frangos de Corte à Síndrome Ascítica. Pesquisa Agropecuária Brasileira, v.39, n.8, p.803-808, 2004.

HOLSHEIMER, J.P.; VEERKAMP, C.M. Effect of Dietary Energy, Protein Level and Lysine Content of on Performance and Yield of two Strains of Male Broiler Chicks. Poultry Science, v.66, n.5, p.872-879, 1992.

MADEIRA, L. A. et al. Morfologia da Fibras Musculares Esqueléticas de Frangos de Corte de Diferentes Linhagens Criados em Sistemas de Confinamento e Semiconfinamento. Revista Brasileira de Zootecnia, v. 35, n. 6, p.2322-2332, 2006.

MARCATO, S. M. et al. Crescimento e Deposição de Nutrientes nos Órgãos de Frangos de Corte de Duas Linhagens Comerciais. Revista Brasileira de Zootecnia, v. 39, n.5, p. 1082-1091, 2010.

MURAKAMI, A. E. et al. Desempenho, Rendimento de Carcaça, Cortes e Desossa de Três Linhagens Comerciais de Frangos de Corte. In: CONFERÊNCIA APINCO DE CIÊNCIA E TECNOLOGIA AVÍCOLAS, 1995, Curitiba. Anais... Campinas: Fundação Apinco de Ciência e Tecnologia Avícolas, 1995. p.279-280.

OLMOS, A. R.. Respostas de Frangos de Corte Fêmeas de duas Linhagens a Dieta com Diferentes Perfis Protéicos Ideais. 58f. Tese (Mestrado em Zootecnia) - Faculdade de Agronomia- Universidade Federal do Rio Grande do Sul, 2008.

PAIVA, A. L. C.et al. Avaliação de Peso Individual e Ganho de Peso de Três Híbridos de Frangos de Cortes. Zootec, Brasília, 2004. 
SANTOS, V. V. A. Avaliação da Concentração de Retinol em Fígados Frescos e Congelados de Frangos das Linhagens Cobb e Ross. 2008. 69f. Tese (Mestrado em Bioquímica) - Centro de Biociências. Universidade Federal do Rio Grande do Norte, 2008.

SOUZA, P.A. et al. Desempenho e Características de Carcaça de Diferentes Linhagens Comerciais de Frango de Corte. Revista da Sociedade Brasileira de Zootecnia, v.23, n.5, p.782-791, 1994.

STRINGHINI, J. H.et al. Avaliação do Desempenho e Rendimento de Carcaça de Quatro Linhagens de Frangos de Corte Criadas em Goiás. Revista Brasileira de Zootecnia, v. 32, n.1,p. 183-190, 2003.

TEIXEIRA, R. B.et al. Avaliação da Conversão Alimentar e Consumo de Ração de Três Híbridos de Frango de Corte. Zootec, Brasília, 2004. 